Thornicroft, G. \& Goldberg, D. (1998) Has Community Care Failed? Maudsley Discussion Paper 5. London: Institute of Psychiatry.

Wall, T. D., Bolden, R. I., Borrill, C. S., et al (1997) Minor psychiatric disorder in NHS trust staff: ccupational and gender differences. British Journal of Psychiatry, 171, 519-523.

Warr, P. (1987) Work, Unemployment and Mental Health. Oxford: Oxford University Press.

\section{Multiple choice questions}

1. Common stressors for community mental health staff include:

a too much paperwork

b conflict with colleagues

c the physical environment of the team base

d travelling to see clients

e fears of violence.

2. The three occupational groups within the NHS with the highest prevalence of psychiatric caseness include:

a occupational therapists

$\mathrm{b}$ managers

c social workers

d doctors

e clinical psychologists.

3. The role of the General Medical Council includes:

a investigation of complaints about doctors by members of the public

b regulation of undergraduate medical training

c support for doctors under investigation

$\mathrm{d}$ advice to medical directors regarding issues of fitness to practice e involvement in the management of the doctor whose performance is impaired owing to illness.

4. Consultant psychiatrists are:

a less prone to burnout than other members of the community mental health team

b likely to identify their colleagues as a source of stress

c more likely to rate as psychiatric cases than juniors

$\mathrm{d}$ identical to other doctors in terms of personality traits

e likely to work longer hours than colleagues in other specialities.

5. Mediating factors that buffer occupational stress include:

a pay levels

b self-esteem

c coping skills

d job satisfaction

e social support.
MCQ answers

\begin{tabular}{|c|c|c|c|c|}
\hline 1 & 2 & 3 & 4 & \\
\hline$T$ & a $F$ & a $\mathrm{T}$ & $\mathbf{a}$ & \\
\hline F & b $\mathrm{T}$ & b $\mathrm{T}$ & $\mathbf{b}$ & T \\
\hline F & c $F$ & c $F$ & & $\mathbf{F}$ \\
\hline F & d $T$ & d $T$ & $\mathbf{d}$ & $F$ \\
\hline $\mathrm{T}$ & e $F$ & e $\mathrm{T}$ & $\mathbf{e}$ & F \\
\hline
\end{tabular}

\title{
Commentary
}

\section{Robert Hale \& Sebastian Kraemer}

This is a timely and useful start to a major debate that should now be taking place in mental health services. The authors have successfully woven the need for staff support into the themes of clinical governance and the national service framework for mental health and other Government initiatives.

Robert Hale (Portman Clinic, 8 Fitzjohn's Avenue, London NW3 5NA) is a consultant psychotherapist and Sebastian Kraemer is Clinical Tutor and a consultant child and adolescent psychiatrist. Both work in the Tavistock and Portman NHS Trust. 
While concentrating on the particular stresses of consultants, they recognise that other grades and other disciplines in the field also suffer.

It is interesting to compare the sources of stress in junior doctors and consultants. For the junior, it is predominantly issues of direct patient care and ethical issues (Firth-Cozens \& Morrison, 1989). By contrast, Isobel Allen (Allen, 1999) describes the multiplicity of tasks which the consultant must perform each with their attendant pressures, responsibilities and sanctions (punishments). As well as providing a clinical service in increasingly hostile circumstances, the consultant must be a manager, accountant, personnel manager, teacher, mentor, researcher, auditor, public relations officer and much more. This leads to what the Harvard organisational psychologist J. J. Gabarro has termed 'role overload'. He compares the corporate organisation, in which the roles are to a large extent performed by separate individuals, with professional services such as law, medicine, and accountancy, in which there is an increasing pressure for those at senior levels to take on this multiplicity of tasks - it is this very multiplicity (frequently in areas for which we have little training) which Gabarro contends leads to burn-out.

What stands out clearly from the text is the experience of helplessness that overwhelms so many colleagues. We might compare the current scene with life in the trenches just over 80 years ago. There men had to survive somehow and obey orders. They were not in a position to question the purposes of the war. Even when they were not themselves injured, many were severely traumatised, leading to a new movement in mental health, well-described by the novelist Pat Barker in her trilogy Regeneration (also now a film). The Tavistock Clinic, which opened in 1920, was born out of these reflections.

The difference between trench war and psychiatry is, of course, that we should have more authority in our work, yet the authors fail to question the very purpose of the enterprise as a whole. Are we going about the task in the right way? It is obvious that mental ill health occurs among the most damaged individuals - those blighted by genetic (and other congenital) disadvantage, loss, poverty, enforced migration, neglect and abuse. We cannot be expected to solve all these problems but, while severe acute mental illnesses clearly involve the brain, it does us no good at all to ignore the psychosocial context. Teasing out causal influences on psychopathology is not simply a diagnostic matter, it is also a philosophical one.

Demoralisation is most likely to occur when people feel that they cannot make any useful difference to the problems presented to them. Animal studies show how lack of a sense of mastery in an experimental condition promotes stress disorders such as peptic ulcer. If psychiatrists felt that they contributed meaningfully to the design of the service they provide, they would have a greater sense of ownership. This goes against the trend of national regulation. If we cannot manage the task, then we become victims, like many of our patients. Clinical governance must be taken up with passion at a local level, otherwise it will be buried in bureaucracy 'psychiatry by numbers'.

Holloway et al emphasise the importance, above all, of regular contact with other consultant staff, both formal and informal. They rightly press for colocation of offices, so that colleagues can meet in each others' rooms and in the corridors, where an enormous amount of unregulated staff support goes on.

There is also, however, a place for more formal reflection between professionals, on their own without trainees. Over the years, the Tavistock Clinic has pioneered the work discussion group, which is facilitated by an experienced clinician, but which works best when members are talking with each other - both supporting and challenging each other (Obholzer \& Roberts, 1994; Foster \& Roberts, 1998). This requires great trust and a certain stability in the service, both of which may be lacking in frontline crisis-driven teams. Some of the College requirements for $\mathrm{CPD}$ - enshrined in this journalcan be met in staff support, which can include specific case discussions as a spur to reviewing and auditing practice. Such meetings, while formal in that they have set times and places, are entirely confidential, and no record of process is kept, although 'action paragraphs' may be agreed from time to time. Appraisal and assessment are necessarily individual and are therefore not covered.

Initiatives of this kind often fail because staff do not want 'therapy', and because senior psychiatrists are often afraid of exposing themselves in front of juniors and other disciplines. Although this requires certain therapeutic skills, it is not therapy (in fact, many practitioners of workplace consultation are not clinically trained at all), and facilitators need to be skilled and generous enough not to put people down. At present, there are too few individuals trained in this work. Team meetings are obviously essential for any service, but we are proposing that consultant psychiatrists in each district set up their own uni-disciplinary groups, to meet with a facilitator every week or two. The group size should not be large - no more than single figures - so that most big mental health trusts would have several groups within them. The task of these meetings would be to review, using case examples, the endlessly engaging concepts of psychiatric practice and the exercise of leadership in modern mental health services. As well as providing support, this would also offer perhaps the best opportunity for self-reflection, innovation and change - the chief antidotes to hopelessness. 


\section{References}

Allen, I. (1999) Stress among Consultants in North Thames. London: N. Thames, Dept Postgrad. Medical \& Dental Education.

Firth-Cozens, J. \& Morrison, L. A. (1989) Sources of stress and ways of coping in junior house officers. Stress Medicine, 5, 121-126.

Foster, A. \& Roberts V. Z. (1998) Managing Mental Health in the Community. London: Routledge.

Obholzer, A. \& Roberts V. Z. (1994) The Unconscious at Work. London: Routledge. 